\title{
REFERENCE LIMITS FOR RETICULOCYTE HAEMOGLOBIN CONTENT IN HEALTHY
} INFANTS

\author{
A. Löfving ${ }^{1}$, O. Andersson ${ }^{1}$, L. Hellström-Westas ${ }^{2}$, M. Domellöf ${ }^{3}$ \\ ${ }^{1}$ Paediatrics, Hallands Hospital, Halmstad, Halmstad, ${ }^{2}$ Department of Women's and Children's Health, \\ Uppsala University, Uppsala, ${ }^{3}$ Department of Clinical Sciences, Paediatrics, Umeå University, Umeå, \\ Sweden
}

Background: Iron deficiency anaemia remains a serious public health problem worldwide, especially in young children. There are many indicators of iron status, which are usually used in combination since they all have limitations. Reticulocyte haemoglobin content (RetHe) is a novel biomarker of iron deficiency but there is a lack of reference limits for RetHe in infants.

Aim: To provide reference limits in healthy infants.

Methods: Swedish infants ( $\mathrm{n}=392)$ born vaginally, at term and in uncomplicated perinatal circumstances were included. RetHe was measured and correlated to Haemoglobin ( $\mathrm{Hb})$, mean cell volume (MCV), mean cell haemoglobin concentration (MCHC), ferritin, soluble transferrin receptor (sTfR) and transferrin saturation (TS).

Results: Of the infants, $46 \%$ were boys, mean (SD) birth weight was $3575( \pm 479)$ grams and mean gestational age was $40,1( \pm 1,1)$ weeks. At 12 months, 324 infants $(85 \%)$ remained in the study. RetHe is presented in Table 1. At 4 months, we found significant correlations $(p<0.001)$ between RetHe and MCV, MCHC, ferritin, sTfR and TS, and at 12 months between RetHe and Hb, MCV, MCHC, sTfR and TS.

\begin{tabular}{|c|c|c|}
\hline & Mean $( \pm$ SD), pg & Reference limits (mean \pm 2SD) \\
\hline \hline Birth & $31.6( \pm 2.1)$ & $27,3-35,9$ \\
\hline 4 months & $29.2( \pm 2,0)$ & $25,1-33,3$ \\
\hline \hline 12 months & $29.0( \pm 2.4)$ & $24,3-33,7$ \\
\hline
\end{tabular}

[Table 1.]

Conclusion: This is the largest study presenting RetHe reference limits for infants. Defining a reference range for RetHe is a first step towards standardizing RetHe as a pre-anaemic biomarker for iron-deficiency in children. 